\title{
Correction to: Theoricity, observation and homology: a response to Pearson
}

\author{
Ariel Jonathan Roffé $^{1}$ (D) Santiago Ginnobili ${ }^{2}$ (D) \\ Daniel Blanco ${ }^{3}$
}

\section{Correction to: HPLS (2018) 40:42 \\ https://doi.org/10.1007/s40656-018-0208-z}

Due to an unfortunate turn of events, the family name of the first author was erroneously published as 'RoffÕ' in the original publication (PDF). The correct representation of the first author's family name is listed above and below.

The original article has been corrected.

The original article can be found online at https://doi.org/10.1007/s40656-018-0208-z.

Santiago Ginnobili

santi75@gmail.com;

https://santi75.wordpress.com

Ariel Jonathan Roffé

arielroffe@ filo.uba.ar;

https://sites.google.com/view/ariel-roffe/

Daniel Blanco

danielblanco.fb@gmail.com

1 National Council of Scientific and Technical Research (CONICET), Center for Philosophy and History of Science (CEFHIC)-National University of Quilmes (UNQ), National University of Tres de Febrero (UNTREF), Buenos Aires, Argentina

2 National Council of Scientific and Technical Research (CONICET), Center for Philosophy and History of Science (CEFHIC)-National University of Quilmes (UNQ), University of Buenos Aires (UBA), Buenos Aires, Argentina

3 National University of the Littoral (UNL), Santa Fe, Argentina 